Syntax Fusion : Jurnal Nasional Indonesia

p-ISSN: -

e-ISSN : 2775-4440

Vol. 1, No. 8, Agustus 2021

\title{
EFEKTIVITAS SISTEM CONSTRUCTED WETLAND SEBAGAI PENGOLAHAN LIMBAH BATIK ECOPRINT MENGGUNAKAN TANAMAN KANGKUNG AIR
}

\section{Yonatan Ananda Salim}

Universitas Kristen Duta Wacana Yogyakarta

Email: yonatan.a.salim@gmail.com

\begin{abstract}
Abstrak
Ecoprint adalah proses mentransfer warna dan bentuk ke kain atau media lain melalui kontak langsung. Walaupun teknik ecoprint berprinsip ramah lingkungan, tetapi pada pembuatannya masih menggunakan zat kimia (tawas, kapur, dan tunjung) serta menghasilkan limbah dari proses perebusan dan pencelupan. Maka dari itu diperlukan sistem pengolahan limbah. Dalam penelitian ini, sistem pengolahan limbah yang digunakan adalah lahan basah buatan (Constructed Wetland). Tipe aliran yang digunakan adalah sistem aliran bawah (Sub-surface Flow / SSF) dan menggunakan tanaman kangkung air (Ipomoea aquatica). Parameter yang diuji adalah BOD, TSS, TDS, besi (Fe), dan pH. Pengambilan sampel dilakukan satu minggu dua kali dengan waktu tinggal selama empat hari dan replikasi dua kali. Hasil persentase efektivitas menunjukkan bahwa BOD menurun sebesar 47\%, TDS menurun sebesar 29\%, TSS menurun sebesar 50\%, dan besi (Fe) menurun sebesar 35\%. Dari penelitian ini dapat diketahui Constructed wetland menggunakan kangkung air dapat menurunkan konsentrasi di setiap parameter.
\end{abstract}

Kata Kunci: Ecoprint, Constructed Wetland, Sub-surface Flow, Kangkung Air

\section{Pendahuluan}

Batik merupakan kain bermotif yang dibuat dari malam menggunakan canting. Pengolahannya diproses dengan cara tertentu. Ada beberapa metode pembuatan batik seperti cap, cetak, printing, dan lain-lain. Perkembangan dan besarnya minat masyarakat dengan batik mengakibatkan terjadinya peningkatan industri batik. Peningkatan industri batik akan mengakibatkan dampak negatif yaitu permasalahan lingkungan akibat limbah batik atau limbah tekstil. Tetapi tren ramah lingkungan juga merambah ke dunia busana. Teknik ecoprint menjadi salah satu alternatif pembuatan produk busana ramah lingkungan. Ecoprint bisa diaplikasikan ke berbagai media yang memiliki serat alami seperti kain (katun, sutera, dan kanvas), kulit, kertas, dan lain-lain. Ecoprint dibuat dengan cara menempelkan tanaman yang memiliki pigmen warna ke kain (media yang 
memiliki serat alami), menggulung, dan mengikatnya, kemudian direbus. Walaupun berprinsip ramah lingkungan, ecoprint menggunakan zat kimia (aluminium sulfat / $\left.\mathrm{Al}_{2}\left(\mathrm{SO}_{4}\right)_{3}\right)$, kapur $\left(\mathrm{Ca}\left(\mathrm{OH}_{2}\right)\right.$ ), dan tunjung (fero sulfat / $\left.\mathrm{FeSO}_{4}\right)$ ) dalam proses pembuatannya dan menghasilkan limbah. Limbah ecoprint ini biasanya langsung di buang ke badan air. Maka dari itu diperlukan sistem yang dapat megolah limbah sebelum di buang ke badan air untuk mengurangi beban pencemar. Salah satu cara pengolahan limbah adalah Constructed Wetland.

Constructed wetland adalah sistem pengolahan terencana atau terkontrol dengan proses alami yang melibatkan vegetasi, media, dan mikroorganisme untuk mengolah limbah (Muhajir, Mika Setiawan. 2013). Konstruksi Constructed Wetland sederhana dan efisien karena memanfaatkan kemampuan tanaman air untuk mengolah limbah. Berbagai jenis tanaman banyak digunakan sebagai penjernih air yang tercemar melalui biofiltrasi. Tanaman air yang digunakan pada sistem ini adalah kangkung air (Ipomoea aquatica). Kelebihan dari tanaman ini adalah sifatnya yang adaptif, daya hidup cukup lama, dan perawatannya mudah. Menurut Anna et al (2013), kangkung air dapat meningkatkan mutu air yang tercemar limbah serta mampu menyerap logam berat yang terlarut dalam media tumbuh. Dari uraian di atas, peneliti ingin mengetahui efetivitas sistem Constructed Wetland sebagai pengolahan limbah batik ecoprint menggunakan tanaman kangkung air.

\section{Metode Penelitian}

Penelitian dilakukan pada bulan September 2020 - Juni 2021, tempat pengujian analisis BOD, TSS, TDS, pH adalah Laboratorium Universitas Kristen Duta Wacana. Pengujian analisis besi (Fe) dilakukan di Laboratorium Balai Besar Teknik Kesehatan Lingkungan dan Pengendalian Penyakit Yogyakarta.

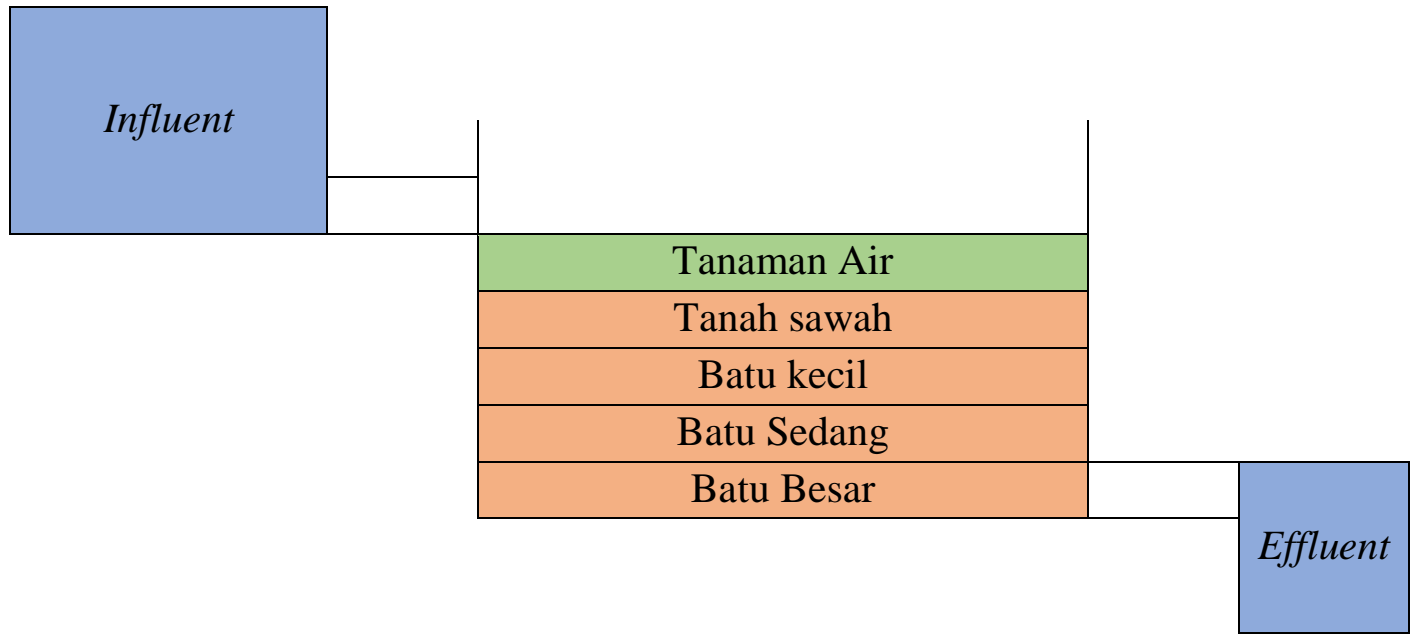

Reaktor diletakkan di samping gor Universitas Kristen Duta Wacana. Dalam desain reaktor ini dilakukan satu perlakuan. Waktu tinggal (Hydraulic Retention Time I HRT) yang digunakan adalah empat hari dan replikasi dua kali. 
Dilakukan setelah kondisi reaktor dalam keadaan stabil atau konstan (steady state). Sampel yang diuji diambil dari influent dan effluent. Parameter yang diukur pada setiap sampel adalah BOD, TSS, TDS, besi (Fe), dan $\mathrm{pH}$.

Alat yang digunakan dalam penelitian adalah jerigen, gayung, corong, aquarium kaca, selang plastik, penjempit infus, sterofom, ember plastik, dan $\mathrm{pH}$ meter. Bahan yang digunakan dalam penelitian adalah kangkung air (Ipomoea aquatica). Media yang digunakan adalah tanah sawah, batu kecil $(0,5-1 \mathrm{~cm})$, batu sedang $(2-3 \mathrm{~cm})$, dan batu besar $(4-5 \mathrm{~cm})$. Limbah yang digunakan adalah limbah batik ecoprint.

Pada bagian inlet, digunakan jerigen dengan kapasitas 50 liter sebagai penampung limbah. Media yang dipakai adalah aquarium yang diisi dengan susunan dari batu besar, batu sedang, batu kecil, tanah sawah dan tanaman air (tanah : batu besar : batu sedang : batu kecil = 9:6:9:3). Waktu tinggal (Hydraulic Retention Time / HRT) yang digunakan adalah 4 hari dengan pengontrolan debit air yang dilakukan setiap hari untuk menjaga stabilitas dari aliran air. Total data masing-masing parameter $(n)=16$ sampel.

\subsubsection{Perhitungan Limbah Yang Dibutuhkan}

Volume Reaktor $\quad=P \times l \times t$

$$
\begin{aligned}
& =25 \mathrm{~cm} \times 20 \mathrm{~cm} \times 27 \mathrm{~cm} \\
& =13.500 \mathrm{~cm}^{3} \approx 13,5 \mathrm{dm}^{3}=13,5 \text { liter }=
\end{aligned}
$$

$13.500 \mathrm{~mL}$

$$
\begin{array}{ll}
\mathrm{HRT} & =4 \text { hari }=5.760 \text { menit } \\
\mathrm{Q} & =\frac{V}{t} \\
& =\frac{13.500 \mathrm{~mL}}{5.760 \text { menit }}=2,3 \mathrm{~mL} / \text { menit }
\end{array}
$$

Kebutuhan limbah dalam 1 hari = 2,3 mL/menit x 60 × $24=3,3$ liter/hari

Tanaman di aklimatisasi dengan air sawah selama 2 minggu sebelum dimasukkan air limbah agar tanaman dapat beradaptasi dengan lingkungan hidup yang baru. Proses pemasukkan limbah ecoprint dilakukan dengan cara mengeluarkan air sawah dari reaktor dan menggantinya dengan air limbah secara bertahap selama 2 minggu.

Limbah dialirkan ke reaktor yang telah diaklimatisasi. Pada uji ini dilakukan pengukuran DO awal untuk mengamati kondisi reaktor sudah mencapai kestabilan dan memperbaiki keadaan aliran air limbah yang masuk dan keluar serta mengamati kondisi media dan tanaman saat dimasukkan air limbah ke dalam reaktor.

Dilakukan setelah kondisi reaktor dalam keadaan stabil atau konstan (steady state). Sampel yang diuji diambil dari influent dan effluent. Parameter yang diukur pada setiap sampel adalah BOD, TSS, TDS, besi (Fe), dan pH. Pengambilan sampel dilakukan satu minggu dua kali dengan waktu tinggal selama empat hari dan replikasi dua kali.

Pengujian BOD dilakukan dengan cara menghitung selisih konsentrasi oksigen terlarut hari ke-0 dan hari ke-5 berdasarkan SNI 6989.72:2009. Langkah pertama adalah disiapkan 2 botol gelap dan diberi label $\mathrm{A}_{1}$ dan $\mathrm{A}_{2}$. Kemudian dimasukkan larutan uji ke dalam masing-masing botol gelap hingga meluap dan ditutup. Botol gelap disimpan 
dalam lemari kedap cahaya selama 5 hari. Kemudian dilakukan pengukuran oksigen terlarut menggunakan DO meter.

Pengujian TSS secara gravimetri berdasarkan SNI 6989.3:2019. Langkah pertama adalah menimbang berat awal kertas saring. Kemudian kertas saring dibasahi dengan larutan uji. Kertas saring dimasukkan ke dalam oven dengan suhu sekitar 103 sampai $105^{\circ} \mathrm{C}$ selama 1 jam. Kemudian kertas saring ditimbang kembali. Untuk mendapat nilai TSS dapat menggunakan rumus sebagai berikut:

$$
\operatorname{TSS}(\mathrm{mg} / \mathrm{L})=\frac{\left(\mathrm{W}_{1}-\mathrm{W}_{0}\right) \times 1000}{\mathrm{~V}}
$$

Keterangan:

$\mathrm{W}_{0} \quad$ = berat awal kertas saring $(\mathrm{mg})$

$\mathrm{W}_{1} \quad=$ berat akhir kertas saring $(\mathrm{mg})$

$1000=$ konversi mililiter ke liter

$\mathrm{V} \quad=$ volume larutan uji $(\mathrm{ml})$

\subsubsection{TDS (Total Dissolved Solid)}

Pengujian TDS secara gravimetri berdasarkan SNI 6989.27:2019. Langkah pertama adalah larutan uji diaduk hingga homogen, kemudian dimasukkan ke dalam alat penyaring. Media penyaring dibilas sebanyak 3 kali dan filtrat dipindahkan ke cawan penguap. Cawan penguap dimasukkan ke dalam oven dengan suhu sekitar $180^{\circ} \mathrm{C}$ selama 1 jam. Untuk mendapat nilai TDS dapat menggunakan rumus sebagai berikut:

$$
\operatorname{TDS}(\mathrm{mg} / \mathrm{L})=\frac{\left(\mathrm{W}_{1}-\mathrm{W}_{0}\right) \times 1000}{\mathrm{~V}}
$$

Keterangan:

$\mathrm{W}_{0} \quad=$ Berat awal kertas saring $(\mathrm{mg})$

$\mathrm{W}_{1}=$ Berat akhir kertas saring $(\mathrm{mg})$

$1000=$ Konversi mililiter ke liter

$\mathrm{V} \quad=$ Volume larutan uji $(\mathrm{ml})$

\subsubsection{Besi (Fe)}

Pengujian besi $(\mathrm{Fe})$ menggunakan Spektrofotometri Serapan Atom (SSA) berdasarkan SNI 6989.4:2009. Langkah pertama adalah larutan uji dihomogenkan, kemudian diambil sebanyak $50 \mathrm{ml}$ untuk dimasukkan ke erlenmeyer $100 \mathrm{ml}$. Ditambahkan $\mathrm{HNO}_{3}$ pekat sebanyak $5 \mathrm{ml}$ dan ditutup menggunakan corong. Erlenmeyer dipanaskan perlahan hingga sisa volume larutannya 15 sampai $20 \mathrm{ml}$. Larutan uji dipindahkan ke labu ukur $50 \mathrm{ml}$ dan ditambahkan air bebas mineral hingga tanda tera. Larutan uji dihomogenkan, kemudian dimasukkan ke dalam SSA dengan panjang gelombang $248.3 \mathrm{~nm}$. Untuk mengukur kadar besi $(\mathrm{Fe})$ dapat menggunakan rumus sebagai berikut:

$$
\mathrm{Fe}(\mathrm{mg} / \mathrm{L})=\mathrm{C} \times \mathrm{fp}
$$

Keterangan:

$\mathrm{C} \quad=$ Kadar yang didapat dari hasil pengukuran $(\mathrm{mg} / \mathrm{L})$ 


$$
\mathrm{fp} \quad=\text { Faktor pengenceran }
$$

\subsubsection{5. $\mathrm{pH}$}

Pengujian pH menggunakan pH meter berdasarkan SNI 6989.11-2019. Langkah pertama adalah elektroda dibilas dengan air bebas mineral, kemudian dikeringkan dengan tisu halus. Elektroda dicelupkan ke dalam larutan uji sampai pH meter menunjukkan nilai yang stabil. Hasil pada $\mathrm{pH}$ meter dicatat dan elektroda dibilas kembali dengan air bebas mineral.

Setelah data hasil uji parameter didapat, dilakukan analisis data menggunakan software Microsoft Excel. Data tersebut dimasukkan ke dalam tabel dan grafik untuk membandingkan jumlah beban organik pada influent dan effluent. Dari tabel dan grafik tersebut dapat diperoleh persentase efektivitas constructed wetland dalam menurunkan beban organik pada limbah ecoprint. Rumus yang digunakan untuk memperoleh persentase efektivitas constructed wetland adalah sebagai berikut:

Keterangan:

$$
\text { Persentase Efektivitas }(\%)=\frac{C_{1}-C_{2}}{C_{1}}
$$

$\mathrm{C}_{1}=$ Konsentrasi Awal

$\mathrm{C}_{2}=$ Konsentrasi Akhir

\section{Hasil Dan Pembahasan}

Penelitian dimulai dengan melakukan aklimatisasi pada tanaman kangkung air. Aklimatisasi dimaksudkan untuk mengadaptasi tanaman dalam sistem lahan basah buatan untuk proses pengolahan limbah. Kangkung air diaklimatisasi dengan air sawah selama 2 minggu. Selanjutnya dimasukkan air limbah ecoprint secara bertahap selama 2 minggu. Setelah tahap aklimatisasi, dilanjutkan tahap uji pendahuluan. Uji pendahuluan dilakukan dengan mengukur oksigen terlarut pada effluent untuk mengukur kestabilan reaktor. Setelah kondisi reaktor stabil, dilakukan pengukuran parameter. Parameter yang diukur adalah BOD, TDS, TSS, pH, dan besi (Fe). Sistem yang digunakan dalam lahan basah buatan adalah Subsurface Flow (SSF) dengan waktu tinggal empat hari. Berikut data pengukuran parameter uji:

Tabel 3. Data Rerata Parameter Uji

\begin{tabular}{ccccc}
\hline Parameter & Influent & Effluent & $\begin{array}{c}\text { Effluent } \\
\text { Removal }\end{array}$ & Baku Mutu \\
\hline BOD & $64 \mathrm{mg} / \mathrm{L}$ & $34 \mathrm{mg} / \mathrm{L}$ & $47 \%$ & $60 \mathrm{mg} / \mathrm{L}$ \\
TDS & $500 \mathrm{mg} / \mathrm{L}$ & $354 \mathrm{mg} / \mathrm{L}$ & $29 \%$ & $2000 \mathrm{mg} / \mathrm{L}$ \\
TSS & $400 \mathrm{mg} / \mathrm{L}$ & $200 \mathrm{mg} / \mathrm{L}$ & $50 \%$ & $50 \mathrm{mg} / \mathrm{L}$ \\
$\mathrm{pH}$ & 6.3 & 6.6 & - & $6.0-9.0$ \\
$\mathrm{Fe}$ & $2.6 \mathrm{mg} / \mathrm{L}$ & $1.7 \mathrm{mg} / \mathrm{L}$ & $35 \%$ & $5 \mathrm{mg} / \mathrm{L}$ \\
\hline
\end{tabular}


Dengan meningkatnya permintaan pasar pada dunia fashion, mengakibatkan industri tekstil menghasilkan banyak limbah. Tidak hanya limbah padat, limbah cair seperti bahan pewarna menjadi permasalahan lingkungan. Limbah cair yang dihasilkan dapat mengandung sisa bahan kimia dalam proses pembuatannya. Oleh dari itu diperlukan sistem yang dapat mengolah limbah sebelum dibuang ke badan air untuk mengurangi beban pencemar.

\subsection{Analisis BOD (Biological Oxygen Demand)}

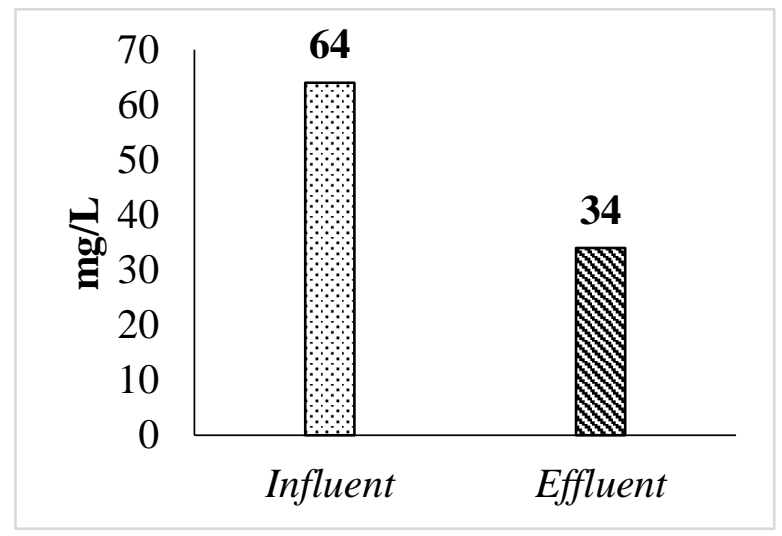

Grafik 4.1. Hasil Analisis BOD

BOD (Biological Oxygen Demand) adalah banyaknya oksigen terlarut yang dibutuhkan mikroorganisme untuk mengurai bahan organik. Nilai BOD (Biological Oxygen Demand) didapat dengan cara menghitung selisih konsentrasi oksigen terlarut hari ke-0 dan hari ke-5. Menurut Retno, et al. (2020), semakin rendah nilai BOD menunjukkan terjadinya penurunan bahan orgnaik pada limbah ecoprint. Nilai BOD biasanya digunakan sebagai salah satu tolak ukur beban organik di dalam limbah. Dalam sistem pengolahan limbah, jika nilai efektivitas BOD semakin tinggi, maka sistem tersebut semakin efisien dalam mengurai bahan organik dalam limbah. Berdasarkan Grafik 4.1 dapat dilihat nilai rata-rata BOD pada influent adalah $64 \mathrm{mg} / \mathrm{L}$ dan pada effluent adalah $34 \mathrm{mg} / \mathrm{L}$ dengan persentase penurunan sebesar 47\%. Dalam sistem constructed wetland, permukaan akar tanaman menjadi habitat mikroorganisme. Maka dari itu, dalam penguraian bahan organik, mikroorganisme dibantu oleh tanaman kangkung air (Ipomoea aquatica). Pada tanaman kangkung air akan terjadi eksudat di zona rhizosfer yang dapat memicu proses degradasi oleh bakteri. Eksudat adalah senyawa yang dikeluarkan melalui akar tanaman dan sebagai bentuk interaksi antara tanaman dan mikroorganisme di akar. Mikroorganisme menggunakan oksigen untuk kelangsungan hidup dan pertumbuhannya, serta dapat meningkatkan kerja bakteri aerob dalam menguraikan bahan organik dalam limbah. Bahan organik yang menurun menyebabkan penggunakan oksigen terlarut berkurang, sehingga nilai BOD dalam limbah menurun. Menurut Nicola, Fendra (2015), konsentrasi TSS yang meningkat menyebabkan 
kekeruhan dalam air limbah. Kekeruhan ini akan menghambat sinar matahari masuk dan proses fotosintesis, serta mengakibatkan berkurangnya oksigen. Hal ini dapat menyebabkan meningkatnya konsentrasi BOD, Jika konsentrasi BOD meningkat, maka nilai DO akan menurun.

\subsection{Analisis TDS (Total Dissolved Solid)}

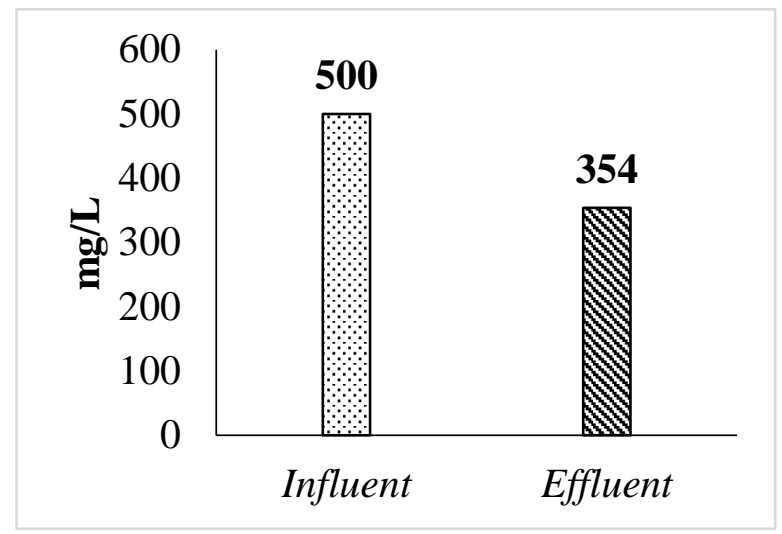

Grafik 4.2. Hasil Analisis TDS

Menurut Rinawati, et al. (2016), TDS (Total Dissolved Solid) mengandung berbagai macam zat terlarut seperti zat organik, zat anorganik, dan materi lainnya dengan diameter kurang dari $10^{-3} \mu \mathrm{m}$ yang terdapat dalam air. Padatan yang terlarut tersebut dapat berasal dari tanah, daun, plankton, dan batuan. Nicola, Fendra (2015) juga menyatakan bahwa TDS adalah jumlah konsentrasi dari ion kation (bermuatan positif) dan ion anion (bermuatan negatif) di dalam air. Nilai TDS yang terlalu tinggi dapat mempengaruhi kualitas air. Tingginya nilai TDS dapat menyebabkan perubahan salinitas. Menurut Arifin, Mursyid (2020), salinitas merupakan konsentrasi total ion yang terdapat di perairan. Salinitas menunjukkan kadar garam di air yang berbanding lurus dengan TDS. Kadar garam yang tinggi pada tanah dapat mengganggu pertumbuhan dan produktivitas tanaman karena dapat menghambat pembesaran dan pembelahan sel. Berdasarkan Grafik 4.2, nilai rata-rata TDS pada influent adalah $500 \mathrm{mg} / \mathrm{L}$ dan pada effluent mengalami penurunan menjadi $354 \mathrm{mg} / \mathrm{L}$ dengan persentase penurunan sebesar 29\%. Menurut Elisa et al. (2020), karena adanya akumulasi padatan terlarut dalam limbah ecoprint, maka terjadi proses penguraian oleh mikroorganisme. Mikroorganisme pada akar tumbuhan dapat mengurai bahan organik menjadi senyawa yang lebih sederhana, sehingga akar tanaman lebih mudah menyerap bahan tersebut.

\subsection{Analisis TSS (Total Suspended Solid)}




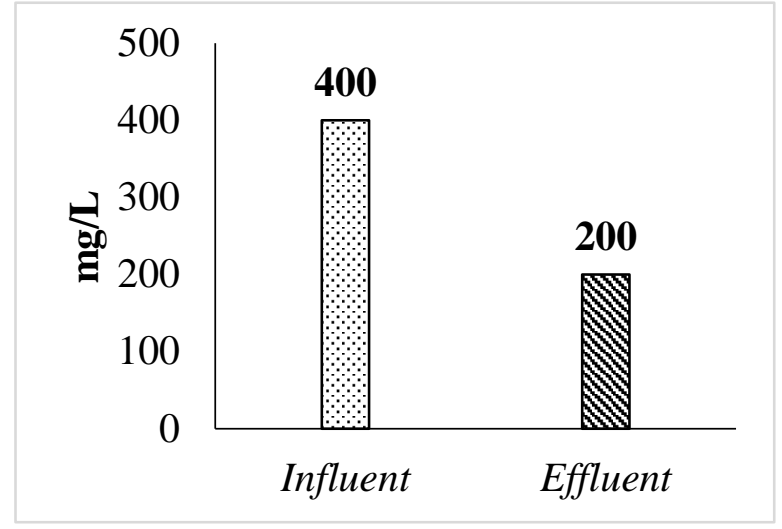

Grafik 4.3. Hasil Analisis TSS

Menurut Riyanda, et al. (2013), TSS (Total Suspended Solid) adalah padatan yang tersuspensi di dalam air yang dapat disaring dengan kertas Millipore berpori. Padatan yang tersuspensi tersebut jika berlebihan akan berdampak buruk terhadap kualitas air karena dapat mengurangi penetrasi sinar matahari ke dalam badan air. Semakin tinggi nilai TSS maka kekeruhan air juga meningkat yang dapat menyebabkan gangguan pertumbuhan bagi organisme produser. Materi padatan yang tersuspensi total (TSS) dapat berupa tanah sawah, lumpur, ganggang, dan bakteri. Menurut Retno, et al. (2020), materimateri tersebut akan melekat pada permukaan tanaman kangkung air yang terendam. Penurunan nilai TSS dalam constructed wetland dapat terjadi dengan proses intersepsi atau penangkapan oleh tanaman dan bisa juga dengan proses sedimentasi. Sistem perakaran pada kangkung air memiliki kemampuan untuk menstabilkan substrat padat di dasar kolam reaktor sehingga dapat berperan dalam proses sedimentasi dan menjaganya agar tidak tersuspensi kembali. Partikel yang lebih besar dan berat akan mengendap dan melewati vegetasi yang ada dalam constructed wetland.

Berdasarkan Grafik 4.3, TSS pada limbah ecoprint belum memenuhi standar baku mutu. Nilai rata-rata TSS pada influent adalah $400 \mathrm{mg} / \mathrm{L}$ dan nilai rata-rata TSS pada effluent adalah $200 \mathrm{mg} / \mathrm{L}$ dengan persentase penurunan sebesar 50\%. Menurut Lia et al. (2016), sistem constructed wetland menggunakan kangkung air belum maksimal karena padatan dalam sistem tersebut masih banyak yang belum mengendap. Banyak padatan yang belum terendap terjadi karena laju aliran air dari influent masih terlalu tinggi yang menyebabkan padatan tersebut belum sempat mengendap dan menempel pada biofilm. Andriyani, Ully (2004) juga menyatakan hal tersebut bisa disebabkan karena jarak tanam kangkung air yang terlalu jauh dan adanya daun atau batang yang jatuh ke dalam reaktor.

\subsection{Analisis pH}




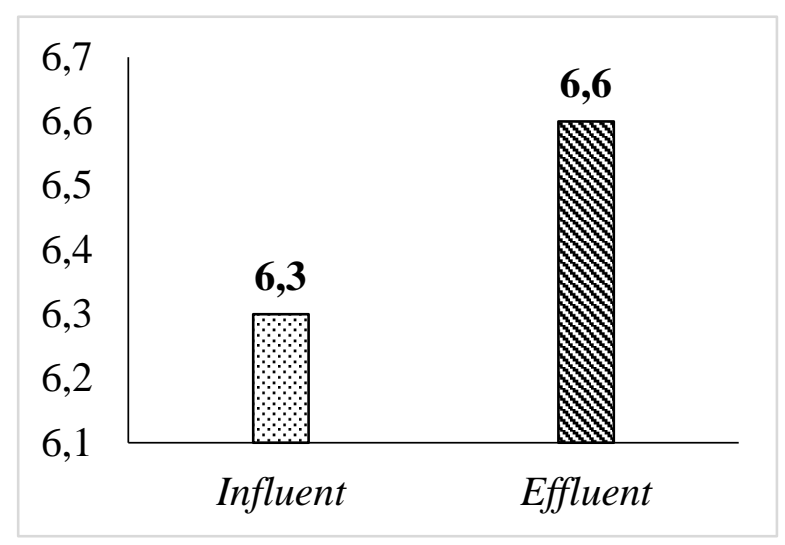

Grafik 4.4. Hasil Analisis $\mathrm{pH}$

Menurut Pamungkas (2016), nilai derajat keasaman atau $\mathrm{pH}$ menunjukkan seberapa besar tingkat keasaman atau kebasaan pada air. $\mathrm{pH}$ dapat diukur pada skala 0 sampai 14. Air dengan nilai $\mathrm{pH}=7$ artinya kondisi air tersebut bersifat netral, air dengan nilai $\mathrm{pH}<7$ artinya kondisi air tersebut bersifat asam, dan air dengan nilai $\mathrm{pH}>7$ artinya kondisi air tersebut bersifat basa. Pengukuran $\mathrm{pH}$ dapat berfungsi sebagai parameter kualitas air, karena dapat mengontrol laju kecepatan reaksi beberapa bahan pada limbah. Berdasarkan Grafik 4.4, nilai rata-rata $\mathrm{pH}$ pada influent adalah 6.3 dan nilai rata-rata $\mathrm{pH}$ pada effluent adalah 6.6 yang artinya limbah ecoprint bersifat asam. Nilai pH pada air dapat mempengaruhi aktivitas mikroorganisme, nilai $\mathrm{pH}$ ideal pada umumnya adalah 6.5 sampai 8.3. Jika nilai $\mathrm{pH}$ terlalu asam atau basa maka mikroorganisme tidak aktif atau mati. Adanya asam mineral bebas dan asam karbonat akan membuat kondisi air menjadi asam, sedangkan adanya karbonat, bikarbonat, dan hidroksida akan membuat kondisi air menjadi basa. Menurut Resmaya, et al. (2017), adanya logam berat pada limbah akan membuat nilai $\mathrm{pH}$ menjadi asam. Semakin besar konsentrasi logam berat pada limbah, maka semakin rendah nilai $\mathrm{pH}$ karena logam berat bersifat asam. Menurut Maya et al. (2019), tanaman kangkung air mensuplai oksigen agar mikroorganisme di dalam sistem dapat mendegradasi bahan organik menjadi cepat.

\subsection{Analisis Besi (Fe)}

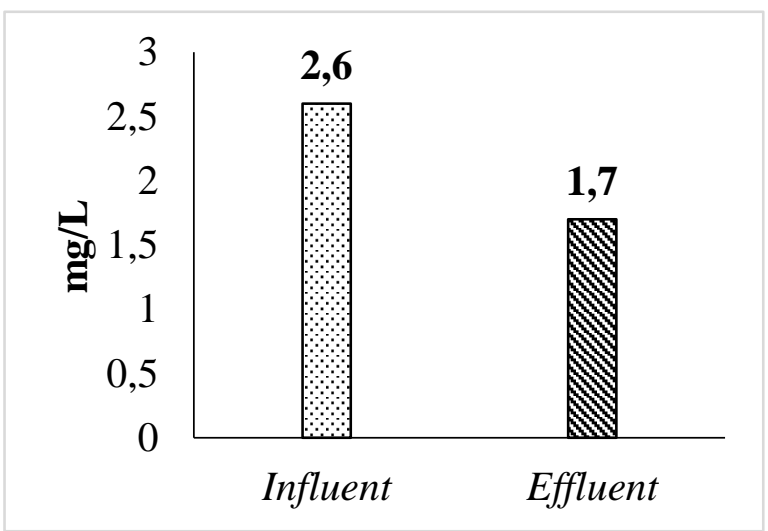

Grafik 4.5. Hasil Analisis Fe 
Menurut Andriani, Ully (2004), besi (Fe) berasal dari pelapukan mineral dan biasanya terdapat pada aluminium, tanah, dan batuan berpasir. Pada air tanah yang tidak mengandung oksigen, besi $(\mathrm{Fe})$ berbentuk $\mathrm{Fe}^{2+}$, sedangkan pada air yang mengalir dan mengalami aerasi $\mathrm{Fe}^{2+}$ teroksidasi menjadi $\mathrm{Fe}^{3+}$. Menurut Ika, et al. (2012), adanya besi (Fe) di air akan mempengaruhi kualitas air dan berbahaya pada kehidupan organisme. Dalam sistem constructed wetland ini, tanaman air yang digunakan adalah kangkung air (Ipomeae aquatica Forsk). Menurut Lusiani, et al. (2017), penyerapan logam berat terdapat pada bagian akar tanaman kangkung, kemudian batang dan daun. Tanaman kangkung melakukan lokalisasi unsur logam pada bagian jaringan tertentu dengan tujuan mencegah keracunan logam berat terhadap sel tumbuhannya atau agar metabolismenya tidak terhambat. Selain itu, tanaman kangkung termasuk dalam rizofiltrasi (tanaman yang menggunakan akar untuk menyerap dan mengakumulasi bahan pencemar). Berdasarkan Grafik 4.5, dapat dilihat rata-rata konsentrasi Fe pada influent adalah $2.6 \mathrm{mg} / \mathrm{L}$ dan pada effluent adalah $1.7 \mathrm{mg} / \mathrm{L}$ dengan persentase penurunan sebesar 35\%. Menurut Andriyani, Ully (2004), pengolahan kadar besi dipengaruhi oleh aktivitas mikroorganisme dalam sistem constructed wetland dan akar tanaman kangkung untuk mensuplai oksigen. Besi (Fe) yang sudah mengalami penguraian oleh mikroorganisme akan menjadi ion $\mathrm{Fe}^{2+}$ yang kemudian diserap oleh akar kangkung air dan menuju batang dan daun. $\mathrm{Fe}^{2+}$ di dalam daun akan digunakan kangkung air untuk proses fotosintesis guna menghasilkan oksigen. Oksigen yang dihasilkan tadi akan digunakan oleh mikroorganisme kembali untuk mengurai bahan organik yang masih ada di dalam sistem constructed wetland. Dengan adanya interaksi tersebut akan terjadi pengurangan bahan organik dan penurunan konsentrasi bahan pencemar dalam limbah ecoprint. Hanafi, et al. (2020) juga menyatakan bahwa air dengan $\mathrm{pH}$ asam / rendah dapat mengakibatkan konsentrasi oksigen terlarut menjadi rendah dan konsentrasi karbondioksida meningkat.

\subsection{Analisis Kualitatif Kangkung Air (Ipomeae aquatica Forsk)}

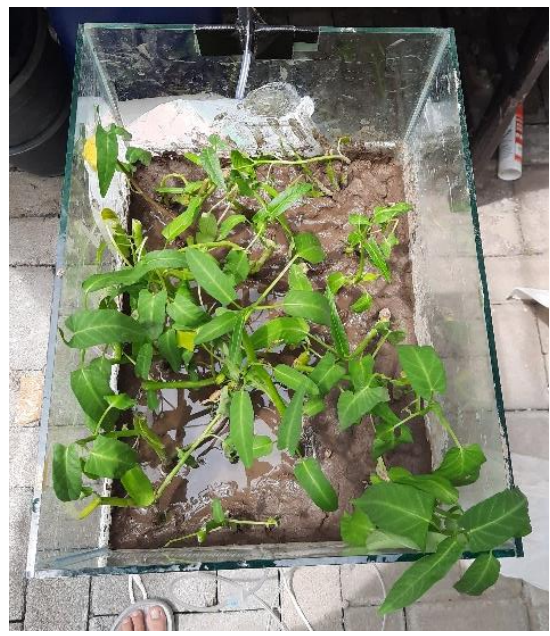

Gambar 1. Aklimatisasi Kangkung Air

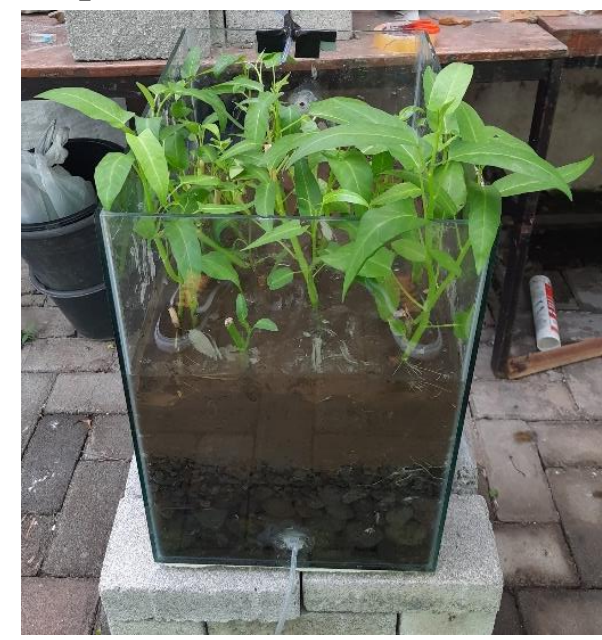

Gambar 2. Aklimatisasi Kangkung Air 


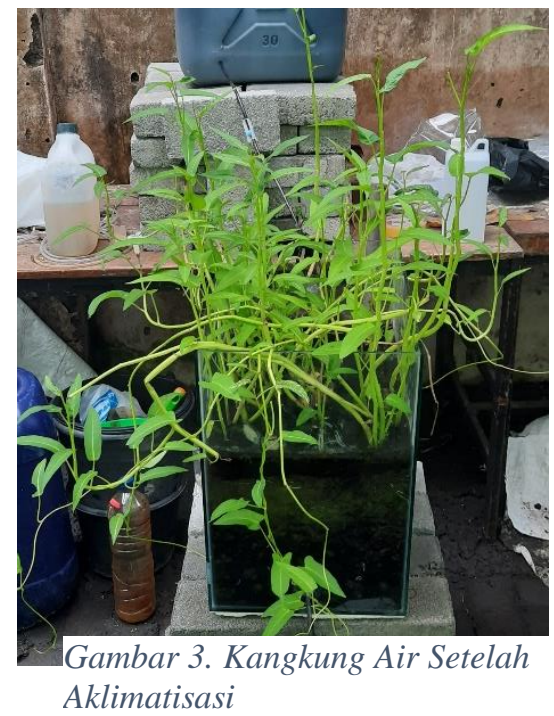

Aklimatisasi merupakan tahap awal agar tanaman kangkung air dapat beradaptasi pada reaktor constructed wetland. Aklimatisasi dilakukan selama 2 minggu dengan memasukkan air sawah terlebih dahulu. Setelah itu dengan komposisi 30\% air limbah dan 70\% air sawah dimasukkan secara bertahap selama 2 minggu sampai tanaman kangkung air dapat tumbuh dan berkembang dengan baik. Dapat dilihat pada Gambar 4.5.1, daun dari kangkung air cukup layu pada hari pertama aklimatisasi. Setelah beberapa hari, dapat dilihat pada Gambar 4.5.2, daun kangkung air sudah tidak layu. Selama proses pengambilan sampel, pada Gambar 4.5.3, batang kangkung air terus bertambah panjang dan ada beberapa daun yang gugur. Hal tersebut sesuai dengan pernyataan Lusiani et al. (2017) bahwa bahan logam yang sudah masuk ke dalam tubuh kangkung air akan dieksresikan dengan cara menggugurkan daun yang sudah tua. Menurut Suryaningsih, et al. (2018), pada kondisi anaerob, kangkung air akan membentuk hormon etilen di pucuk dan akar tanaman. Hormon etilen dapat meningkatkan aktivitas enzim selulase guna membentuk jaringan aerenkim.

\section{Kesimpulan}

Dalam sistem pengolahan limbah constructed wetland menggunakan kangkung air (Ipomoea aquatica) dapat mengolah limbah ecoprint. Hal tersebut dapat dilihat dari menurunnya nilai BOD yang awalnya $64 \mathrm{mg} / \mathrm{L}$ menjadi $34 \mathrm{mg} / \mathrm{L}$ dengan persentase penurunan $47 \%$, nilai TDS yang awalnya $500 \mathrm{mg} / \mathrm{L}$ menjadi $354 \mathrm{mg} / \mathrm{L}$ dengan persentase penurunan $29 \%$, nilai TSS yang awalnya $400 \mathrm{mg} / \mathrm{L}$ menjadi $200 \mathrm{mg} / \mathrm{L}$ dengan persentase penurunan $50 \%$, nilai $\mathrm{pH}$ yang awalnya 6.3 menjadi 6.6 , dan nilai besi (Fe) yang awalnya $2.6 \mathrm{mg} / \mathrm{L}$ menjadi $1.7 \mathrm{mg} / \mathrm{L}$ dengan persentase penurunan $35 \%$. 


\section{Bibliografi}

Andriyani, Ully. 2004. Studi Pengolahan Limbah Cair Industri Pengalengan Jamur Dengan Reaktor Constructed Wetland Menggunakan Tanaman Kangkung Air (Ipomoea aquatica Forsk), hlm 20-23. Yogyakarta: Fakultas Teknik Sipil dan Perencanaan, Universitas Islam Indonesia.

Anna et al. 2013. Pengolahan Limbah Domestik Dengan Teknologi Taman Tanaman Air (Constructed Wetlands). Vol. 2 (2), hlm. 72. Malang: Fakultas Teknik, Universitas Katholik Widya Karya.

Arifin, Mursyid Anwar. 2020. Keragaman Salinitas, TDS, pH Air dan Tanah, serta Produksi Padi di Lahan Sawah di Desa Purwa Agung, Kecamatan Lalan, Kabupaten Musi Banyuasin. Palembang: Fakultas Pertanian, Universitas Sriwijaya.

Elisa et al. 2020. Pengukuran Total Dissolved Solid (TDS) Dalam Fitoremidiasi Deterjen

Dengan Tumbuhan Sagittaria lancifolia. Vol. 7 (1). Surabaya: Fakultas

Matematika dan Ilmu Pengetahuan Alam, Universitas Negeri Surabaya.

Fazruza, Murizar et al. 2018. Eksplorasi Daun Jati Sebagai Zat Pewarna Alami Pada

Kain Katun Sebagai Produk Pashmina Dengan Teknik Ecoprint, Vol. 3 (3), hlm.

4. Banda Aceh: Fakultas Keguruan dan Ilmu Pendidikan, Universitas Syiah Kuala Darussalam.

Fitri, Nurul. 2017. Sintesis Kristal Tawas [KAI( $\left(\mathrm{SO}_{4}\right)_{2} .12 \mathrm{H}_{2} \mathrm{O}$ ] Dari Limbah Kaleng Bekas

Minuman. Makassar: Fakultas Sains dan Teknologi, Universitas Islam Negeri Alauddin.

Hanafi et al. 2020. Pengaruh Tumbuhan Kabomba (Cabomba aquatica Aubl.) Terhadap

Kadar Logam Besi ( $\mathrm{Fe}$ ) dan Tembaga (Cu) Limbah Cair Laboratorium Kimia

FMIPA UNTAN. Vol. 12 (1). Kalimantan Barat: Fakultas MIPA, Universitas

Tanjungpura.

Hariani et al. 2009. Penurunan Konsentrasi Cr(VI) Dalam Air Dengan Koagulan FeSO 4.

Vol. 12 (2). Palembang: Fakultas MIPA, Universitas Sriwijaya.

Jaswinder Kaur et al. 2016. Taxonomy, Phytochemistry, Traditional Uses and Cultivation

of Ipomoea aquatica Forsk. Vol. 2, hlm. 412. India: Department of Botany, University of Allahabad.

Lia et al. 2016. Uji Efektivitas Pengolahan Air Limbah Rumah Sakit Pertamedika

Menggunakan Sistem Biofilter Aerob-Anaerob. Vol. 9 (2). Kalimantan Utara:

Fakultas Perikanan dan Ilmu Kelautan, Universitas Borneo Tarakan.

Lusiani et al. 2017. Potensi Tanaman Kangkung Air (Ipomoea aquatica) Sebagai

Bioabsorpsi Logam $\mathrm{Pb}$ dan $\mathrm{Cu}$. Gorontalo: Fakultas Matematika dan IPA, Universitas Gorontalo.

Maya et al. 2019. Pemanfaatan Lemna minor L. dan Hydrilla verticillate (L.f.) Royle

Untuk Memperbaiki Kualitas Air Limbah Laundry. Vol. 8 (1). Pontianak: Fakultas MIPA, Universitas Tanjungpura. 
Muhajir, Mika Septiawan. 2013. Penurunan Limbah Cair BOD Dan COD Pada Industri Tahu Menggunakan Tanaman Cattail (Typha angustifolia) Dengan Sistem Constructed Wetland. Hlm. 16-18. Semarang: Fakultas Matematika Dan Ilmu Pengetahuan Alam, Universitas Negeri Semarang.

Nicola, Fendra. 2015. Hubungan Antara Konduktivitas, TDS (Total Dissolved Solid) dan TSS (Total Suspended Solid) Dengan Kadar Fe $e^{2+}$ dan Fe Total Pada Air Sumur Gali. Jember: Fakultas Matematika dan Ilmu Pengetahuan Alam, Universitas Jember.

Pamungkas, M. T. O. A..2016. Studi Pencemaran Limbah Cair Dengan Parameter BOD 5 dan pH di Pasar Ikan Tradisional dan Pasar Modern di Kota Semarang. Vol. 4 (2). Semarang: Fakultas Kesehatan Masyarakat, Universitas Diponegoro.

Peraturan Daerah Istimewa Yogyakarta Nomor 7 Tahun 2016 Tentang Baku Mutu Air Limbah. Hlm. 17.

Renata, Leny Erisna Putri. 2014. Pengolahan Limbah Cair Kain Jumputan Dengan Menggunakan Membran Komposit Kitosan-PV A. hlm. 6. Palembang: Jurusan Teknik Kimia, Politeknik Negeri Sriwijaya.

Resmaya et al. 2017. Kemampuan Tanaman Kangkung Air (Ipomoea aquatica) Dalam Menyerap Logam Berat Kadmium (Cd) Berdasarkan Konsentrasi dan Waktu Pemaparan Yang Berbeda. Surabaya: Fakultas Matematika dan Ilmu Pengetahuan Alam, Universitas Negeri Surabaya.

Retno et al. 2020. Efektivitas Tanaman Lembang (Typha angustifolia L.) di Lahan Basah Buatan Dalam Penurunan Kadar TSS, BOD, dan Fosfat Pada Air Limbah Industri Laundry. Jember: Fakultas Matematika dan Ilmu Pengetahuan Alam, Universitas Jember.

Riyanda et al. 2013. Kajian Karakteristik Kimia Air, Fisika Air, dan Debit Sungai Pada Kawasan DAS Padang Akibat Pembuangan Limbah Tapioka. Vol. 1 (3), hlm. 618. Medan: Fakultas Pertanian, Universitas Sumatera Utara.

Saptutyningsih, Endah et al. 2019. Pemanfaatan Bahan Alami Untuk Pengembangan Produk Ecoprint di Dukuh IV Cerme, Panjatan, Kabupaten Kulonprogo, hlm. 19. Yogyakarta: Fakultas Ekonomi dan Bisnis, Universitas Muhammadiyah Yogyakarta.

Saswita, Neni et al. 2018. Penggunaan Kapur Tohor (CaO) Dalam Penurunan Kadar Logam Fe dan Mn Pada Limbah Cair Pewarnaan Ulang Jeans Kabupaten Magelang Tahun 2017. Vol. 6 (1). Semarang: Fakultas Kesehatan Masyarakat, Universitas Diponegoro.

Suryaningsih et al. 2018. Analisis Kadar Kalsium (Ca) dan Besi (Fe) Dalam Kangkung Air (Ipomeae aquatica Forsk) Asal Palu. Vol. 7 (3). Palu: Pendidikan Kimia/FKIP, Universitas Tadulako. 